\title{
Improving System Wide Hospital Efficiency at the Community Level
}

\author{
Ronald Lagoe ${ }^{*}$, Maud White ${ }^{2}$, Shelly Littau1 \\ ${ }^{1}$ Hospital Executive Council, Syracuse, NY, USA \\ ${ }^{2}$ Crouse Health Network, Syracuse, NY, USA \\ Email: *Hospexcl@cnymail.com
}

Received 22 June 2016; accepted 18 July 2016; published 21 July 2016

Copyright (C) 2016 by authors and Scientific Research Publishing Inc.

This work is licensed under the Creative Commons Attribution International License (CC BY). http://creativecommons.org/licenses/by/4.0/

(c) (i) Open Access

\section{Abstract}

This study reviewed programs to improve the efficiency of hospital utilization in the metropolitan area of Syracuse, New York between 1998 and 2015. It involved indicators that were largely under the control of hospitals and their nursing and administrative staffs, such as inpatient stays and post admission complications, as well as programs where there was less provider control such as inpatient admissions and readmissions. Large reductions in inpatient lengths of stay were generated by the Syracuse hospitals, contributing to a decline in the average daily adult medicine and adult surgery census of 140 patients. Reductions in post admission complications contributed to these developments. The study suggested that efforts to reduce inpatient admissions in the Syracuse hospitals had limited results. The areas hospital admission rate was conservative, but approximately 2000 resident discharges per year above that of a neighboring community. The need for reduction of hospital admissions resulted from the absence of provider or payor efforts to develop alternative resources in the community. If the experience of the Syracuse hospitals is typical, improvement of the efficiency of community health systems will require creativity and resources from providers. Perhaps more importantly, health care payors will need to assume an active role in these efforts.

\section{Keywords}

Hospitalization, Hospital Lengths of Stay, Hospital Outcomes, Health Care Costs

\section{Introduction}

In the United States, increased attention is focusing on improving the efficiency of hospital utilization. These

${ }^{*}$ Corresponding author. 
efforts have important implications for nursing and administrative managers in health care. Historically, this interest has developed because hospitals are responsible for a large proportion of health care expenses [1] [2].

Much of the initiative to improve efficiency has been generated by health care providers. Because inpatient reimbursement is based on prospective payments, regardless of the amount of related expenses, hospitals have an interest in reducing costs.

Provider sponsored efforts to improve efficiency have tended to focus on areas where hospital control and the impact of clinical management is maximized, such as the reduction of inpatient stays and post admission complications. Shorter stays are usually associated with lower costs, especially for patients discharged home and without extensive long term care services. Inpatient complications can frequently be reduced because the hospital controls the patient environment [3]-[6].

In recent years, the interest of payers in improving health care efficiency has also increased. This has been stimulated by the efforts of public and private payers to control their own expenses, as well as the notion that efficient care is frequently better care [7] [8]. A number of payer sponsored efforts to improve hospital efficiency have been based on reduction of inpatient admissions. Administrative data have demonstrated that large differences in admissions and discharges per population exist in the United States. This information has been reinforced by rising interest in population health and population health care. These initiatives have also included programs implemented by health care payers that penalize hospitals for excessive readmissions [9].

These developments have important implications for nursing and health care management. They are being played out in local health care systems within the United States. They include programs for implementation within hospitals and those that require involvement of providers and payers at the community level.

\section{Population}

The study evaluated the impact of efforts to improve the efficiency of care in the hospitals of Syracuse, New York through internal services and through services in the community. The Syracuse area includes three acute care facilities, Crouse Hospital (19,776 discharges excluding well newborns, 2015), St. Joseph's Hospital Health Center (24,803 discharges, 2015), and Upstate University Hospital (28,237 discharges, 2015). The hospitals work with a combined medical staff of over 1800 physicians and 12 local nursing homes.

The Syracuse hospitals provide primary and secondary acute care to the metropolitan area with a population of approximately 600,000. They provide tertiary services to the Central New York Health Service Area with a population of approximately 1,400,000 [10].

Historically, the Syracuse hospitals have worked cooperatively to improve the efficiency of acute care through initiatives that focus largely on inpatient acute care and through initiatives that involve services in the community. A number of these initiatives have been developed through their cooperative planning organization, the Hospital Executive Council [11].

Efforts to improve efficiency through internal services have included reduction of inpatient stays and post admission complications. Length of stay reduction programs have been implemented in all of the hospitals beginning in 1983. Efforts to address inpatient complications have been addressed by a cooperative program with 3M ${ }^{\mathrm{TM}}$ Health Information Systems between 2010 and 2014 [12].

A number of efforts of the Syracuse hospitals to improve the efficiency of acute care through services in the community involve reduction of inpatient admissions. Historically, providers and payers in the community decided against construction of another acute hospital and the development of additional ambulatory care services. This contributed to the efficiency of inpatient acute care for years. More recently, major health care payers such as Medicaid and Blue Cross have attempted to reduce inpatient hospital utilization at the regional and local levels.

\section{Method}

This study evaluated the impact of efforts to improve the efficiency of hospital utilization in the metropolitan area of Syracuse, New York over a multi year period. It focused on programs that largely involved activities within hospitals, reduction of inpatient stays and post admission complications, and programs that required involvement of services in the community, reduction of inpatient admissions and readmissions.

The study was carried out using patient specific data from each of the hospitals by the Hospital Executive Council. These data were obtained through Business Associate Agreements with each of the hospitals. The 
Council functions as a mechanism for the development of multihospital studies in the Syracuse metropolitan area.

The evaluation of utilization and outcomes indicators in this study focused on changes in longitudinal data for the Syracuse hospitals. These comparisons identified the development of each of the study indicators over time. Through these comparisons, it was possible to identify the impact of each of the indicators on hospital admissions or patient days through time periods. Where useful comparison information from larger populations was available, such as national mean lengths of stay and admission rates for New York State metropolitan areas, this information was used in the analysis.

Efforts to reduce inpatient stays in the Syracuse hospitals focused on adult medicine and adult surgery patients, who account for more than 70 percent of utilization in the hospitals. The study data included adult medicine and adult surgery lengths of stay for the combined hospitals for the period 1998-2015. For each service, the hospital stays were compared with the severity adjusted national average to identify differences in stays and patient days. The All Patients Refined Severity of Illness System developed by $3 \mathrm{M}^{\mathrm{TM}}$ Health Information Systems was used to identify the severity adjusted differences [13].

Efforts to reduce post admission inpatient complications in the Syracuse hospitals focused on adult medicine and adult surgery patients for the period 2008-2015. The study data were based on complication rates, based on numbers of post admission complications divided by total at risk populations for Crouse Hospital and St. Joseph's Hospital Health Center, which participated in a community wide demonstration program addressing this indicator between 2008 and 2014. This analysis was based on the Potentially Preventable Complications software developed by $3 \mathrm{M}^{\mathrm{TM}}$ Health Information Systems [14].

Efforts to address inpatient hospital admission rates in the Syracuse hospitals focused on adult medicine, adult surgery, and pediatric patients including neonates for New York State metropolitan counties. The study data were based on resident hospital discharges for the period 2007-2015. This analysis included all hospital admissions except obstetrics, to control for variations in birth rates, and mental health, because data were not available for New York State psychiatric hospitals. The patient populations were identified using the All Patients Refined Diagnosis Related Groups developed by 3M${ }^{\mathrm{TM}}$ Health Information Systems and demographic data collected from the New York Statewide Planning and Research and Cooperative System.

Efforts to address inpatient readmissions in the hospitals of Syracuse, New York focused on adult medicine and adult surgery patients between January 2013 and February 2016. Quarterly data for each of the three Syracuse hospitals were used to evaluate changes in readmission rates and related utilization. This information was analyzed using the Potentially Preventable Readmissions software developed by $3 \mathrm{M}^{\mathrm{TM}}$ Health Information Systems.

\section{Results}

The initial component of the study focused on reduction of inpatient lengths of stay for adult medicine and adult surgery, the largest inpatient services in the Syracuse hospitals. Relevant data are summarized in Table 1.

These data demonstrated that considerable reductions in inpatient stays and related utilization occurred in the Syracuse hospitals between 1998 and 2008. The mean length of stay for adult medicine declined from 5.89 to 4.98 days. This resulted in a change from 36,653 to 8569 days above the severity adjusted national average. This amounted to a savings of 28,084 patient days or an average daily census of 76.9 patients.

The mean length of stay for adult surgery declined from 6.66 to 6.23 days between 1998 and 2008. This resulted in a change from 24,924 to 11,544 days above the severity adjusted national average. This amounted to a savings of 13,380 patient days or an average daily census of 36.7 patients.

These substantial reductions in stays in the Syracuse hospitals occurred through provider efforts to reduce stays for discharges home and to long term care services in the community. They were stimulated by the change in hospital reimbursement from payments per day to payments per discharge by Medicare and other health care payers.

Since 2008, efforts to reduce inpatient stays have continued in the Syracuse hospitals. The data in Table 1 demonstrated that stays for adult medicine increased from 4.98 days in 2008 to 5.45 days in 2014. This development was caused by the difficulty of generating further reductions in stays and by the shift of some Medicare patients at low severity of illness to Medical Observation status in 2013. This caused the stays for the remaining adult medicine populations to increase. For adult surgery, where this change did not apply, provider efforts supported a further reduction in stays from 6.23 to 6.04 days between 2008 and 2014. 
Table 1. Inpatient mean lengths of stay, adult medicine and adult surgery, Syracuse Hospitals, 1998, 2008, 2010, 2012, 2014.

\begin{tabular}{|c|c|c|c|c|c|}
\hline & 1998 & 2008 & 2010 & 2012 & 2014 \\
\hline \multicolumn{6}{|l|}{ Adult Medicine } \\
\hline Number of Discharges & 25,278 & 28,565 & 32,221 & 35,274 & 33,421 \\
\hline Mean Length of Stay (Days) & 5.89 & 4.98 & 5.18 & 5.14 & 5.45 \\
\hline Severity Adjusted National Average & 4.44 & 4.68 & 4.84 & 5.00 & 5.20 \\
\hline Length of Stay Difference & 1.45 & 0.30 & 0.34 & 0.14 & 0.25 \\
\hline Patient Days Difference & $36,653.10$ & 8569.50 & $10,955.14$ & 4938.36 & 8355.25 \\
\hline \multicolumn{6}{|l|}{ Adult Surgery } \\
\hline Number of Discharges & 20,100 & 19,241 & 19,170 & 20,439 & 20,562 \\
\hline Mean Length of Stay (Days) & 6.66 & 6.23 & 6.25 & 6.04 & 6.04 \\
\hline Severity Adjusted National Average & 5.42 & 5.63 & 5.89 & 5.75 & 5.95 \\
\hline Length of Stay Difference & 1.24 & 0.60 & 0.36 & 0.29 & 0.09 \\
\hline Patient Days Difference & $24,924.00$ & $11,544.60$ & 6901.20 & 5927.31 & 1850.58 \\
\hline
\end{tabular}

Adult medicine data exclude Diagnosis Related Groups concerning surgery, obstetrics, pediatrics, psychiatry, alcohol/substance abuse treatment, rehabilitation, and all patients aged 0 - 17 years. Adult surgery data exclude Diagnosis Related Groups concerning medicine, obstetrics, pediatrics, psychiatry, alcohol/substance abuse treatment, and all patients aged 0 - 17 years. Source: Hospital Executive Council.

The reductions in stays for both major hospital services produced considerable declines in excess patient days in the combined Syracuse hospitals compared with severity adjusted national averages between 1998 and 2014. For adult medicine, the number of excess days declined by 28,298, or an average daily census of 77.5. For adult surgery, the number of excess days declined by 23,074, or an average daily census of 63.2. Length of stay reduction in the combined services produced a reduction in the average daily census of more than 140 patients.

Since 2008, the Syracuse hospitals developed programs to reduce stays for discharges to nursing homes, the major remaining source of excess stays. The impact of these programs, focusing on Difficult to Place and Complex Care patients, has been more visible in adult surgery because of the effect of the Medical Observation Program in adult medicine.

The second component of the study focused on reduction of post admission complications for two of the Syracuse hospitals between 2009 and 2014. Relevant data are summarized in Table 2.

This information concerned an outcomes indicator that was largely under the control of the hospitals. Post admission complications could, at least theoretically, be limited through infection control and other quality assurance programs.

The study data demonstrated that aggregate complications per 1000 at risk discharges declined from 42.65 to 28.13 at Crouse Hospital and from 56.31 to 32.91 at St. Joseph’s Hospital Health Center between 2009 and 2012. This was the initial period of the demonstration program involving the hospitals and $3 \mathrm{M}^{\mathrm{TM}}$ Health Information Systems. The data also demonstrated that, between 2012 and 2014, the aggregate complication rate at Crouse Hospital did not exceed 29.12 and the rate at St. Joseph’s Hospital Health Center did not exceed 34.87.

Additional study data for individual complication rates at the two hospitals reinforced this information. For pneumonia, between 2009 and 2012, the rate at Crouse Hospital declined from 6.40 to 3.68 while the rate at St. Joseph's Hospital Health Center declined from 13.16 to 8.15. After 2012, the rates for pneumonia did not exceed 4.81 at Crouse Hospital and 10.06 at St. Joseph's. For urinary tract infection between 2009 and 2012, the rate at Crouse Hospital declined from 8.80 to 7.68, while the rate at St. Joseph's declined from 9.03 to 5.29. After 2012, the rates for urinary tract infection did not exceed 7.14 at Crouse Hospital and 6.61 at St. Joseph's.

The third component of the study concerned hospital admission/discharge rates in the Syracuse hospitals. Data comparing rates for New York State metropolitan areas are summarized in Table 3. These rates include all discharges except obstetrics, because of variations in birth rates, and mental health, because information concerning State psychiatric centers was not available.

These data demonstrated that the hospitalization rates for the six New York State metropolitan areas covered a considerable range. During the eight year period, this range declined from 30.8 in 2007 to 14.6 in 2015, from 
Table 2. Potentially Preventable Complication rates per 1000 discharges, Crouse Hospital and St. Joseph's Hospital Health Center, 2009-2014.

\begin{tabular}{lccccccc}
\hline & 2009 & 2010 & 2011 & 2012 & 2013 & 2014 & 2015 \\
\hline Crouse Hospital & & & & & & & \\
Total & 42.65 & 37.14 & 34.14 & 28.13 & 29.12 & 27.56 & 27.60 \\
Pneumonia & 6.40 & 5.73 & 4.21 & 3.68 & 4.38 & 4.81 & 3.12 \\
Urinary Tract Infection & 8.80 & 7.21 & 9.30 & 7.68 & 7.14 & 6.05 & 5.28 \\
St. Joseph's Hospital Health Center & & & & & & & \\
Total & 56.31 & 47.28 & 37.37 & 32.91 & 33.31 & 34.87 & 34.20 \\
Pneumonia & 13.16 & 10.85 & 7.64 & 8.15 & 9.25 & 8.69 & 10.06 \\
Urinary Tract Infection & 9.03 & 8.78 & 6.39 & 5.29 & 5.15 & 6.61 & 4.72 \\
\hline
\end{tabular}

Table 3. Resident inpatient hospitalization rates per 1000 population, medical/surgical and pediatric/neonatal, New York state metropolitan areas.

\begin{tabular}{lccccc}
\hline Resident County & 2007 & 2009 & 2011 & 2013 & $2015^{*}$ \\
\hline Albany County & 90.7 & - & - & - & - \\
Capital District (Albany, Schenectady, Rensselaer) & - & 88.6 & 86.8 & 66.1 & 77.5 \\
Erie County (Buffalo) & 99.3 & 94.5 & 81.1 & 84.5 & 80.6 \\
Monroe County (Rochester) & 82.5 & 86.3 & 85.3 & 78.8 & 77.3 \\
New York City (5 Burroughs) & 101.8 & 95.7 & 87.3 & 90.7 & 81.9 \\
Oneida County (Utica) & 113.3 & 110.9 & 104.6 & 94.9 & 91.9 \\
Onondaga County (Syracuse) & 84.2 & 81.3 & 86.4 & 84.2 & 80.7 \\
\hline
\end{tabular}

*Data annualized based on January-June 2015 actual experience. Data do not include obstetrics (APR DRGs 540-566), mental health/substance abuse treatment (APR DRGs 740-776), and rehabilitation (APR DRG 860). Prepared by: Hospital Executive Council.

the highest to the lowest rate for each year. This occurred as excess admissions were eliminated and statewide rates converged at more efficient levels.

Among the metropolitan areas of Syracuse and the other communities, the highest hospital admission/discharge rates were generated by New York City and Utica. During the period, the rates for these communities declined by more than 20 discharges per population, probably reflecting the impact of payer and provider initiatives on excess admissions.

Among the metropolitan areas of Syracuse and the other communities, the admission rates of Rochester and most recently Albany were relatively low. This may have reflected the impact of managed care plans located in both of these areas.

For the most recent years of the study data, the hospitalization rates for the Syracuse metropolitan area were slightly higher than those of Rochester and Albany. Between 2011 and 2015, for example, the difference between the rates for Syracuse and Rochester ranged from 1.1 to 5.4 discharges per 1000 population. These differences were much smaller than the statewide ranges. Based on the population of the Syracuse metropolitan area, they amounted to approximately 495 - 2430 additional discharges per year. They may have probably resulted from the fact that the rates for Syracuse were generated by hospitals, without much impact from managed care organizations. The absence of alternatives to hospital services in the community probably also contributed.

The fourth component of the analysis focused reduction of inpatient readmissions within 30 days of the initial admissions for adult medicine and adult surgery in the Syracuse hospitals between January 2013 and February 2016. Relevant data are summarized in Table 4.

These data demonstrated that inpatient readmissions in each of the Syracuse hospitals declined during the 38 month period. The sizes of these reductions ranged from less than one day at St. Joseph’s Hospital Health Center and Upstate University Hospital to almost two days at Crouse Hospital.

At the same time, the data demonstrated that these declines occurred as cyclical reductions at each of the hospitals. Eight of these reductions included two quarters, three included three quarters, and two included four 
Table 4. Potentially Preventable Readmissions, adult medicine and adult surgery patients, all payors, Syracuse hospitals by quarter.

\begin{tabular}{|c|c|c|c|c|c|c|c|c|c|}
\hline & \multicolumn{3}{|c|}{ Crouse Hospital } & \multicolumn{3}{|c|}{ St. Joseph's Hospital Health Center } & \multicolumn{3}{|c|}{ Upstate University Hospital - SUNY UMU } \\
\hline & $\begin{array}{c}\text { Number of } \\
\text { Readmissions }\end{array}$ & $\begin{array}{l}\text { Readmission } \\
\text { Rate }\end{array}$ & $\begin{array}{l}\text { Declining } \\
\text { Cycles }\end{array}$ & $\begin{array}{c}\text { Number of } \\
\text { Readmissions }\end{array}$ & $\begin{array}{l}\text { Readmission } \\
\text { Rate }\end{array}$ & $\begin{array}{l}\text { Declining } \\
\text { Cycles }\end{array}$ & $\begin{array}{c}\text { Number of } \\
\text { Readmissions }\end{array}$ & $\begin{array}{l}\text { Readmission } \\
\text { Rate }\end{array}$ & $\begin{array}{l}\text { Declining } \\
\text { Cycles }\end{array}$ \\
\hline 1Q 2013 & 248 & 7.55 & - & 462 & 8.36 & - & 362 & 7.47 & \\
\hline 2Q 2013 & 245 & 7.48 & - & 392 & 6.90 & 2 & 401 & 7.90 & \\
\hline 3Q 2013 & 216 & 6.96 & 3 & 447 & 8.05 & - & 400 & 8.15 & - \\
\hline 4Q 2013 & 258 & 7.90 & - & 433 & 7.89 & 2 & 290 & 6.41 & 2 \\
\hline 1Q 2014 & 211 & 6.95 & 2 & 443 & 8.32 & - & 342 & 7.66 & - \\
\hline 2Q 2014 & 254 & 7.62 & - & 286 & 7.66 & 2 & 345 & 7.38 & 2 \\
\hline 3Q 2014 & 231 & 6.86 & - & 439 & 8.00 & & 363 & 7.68 & - \\
\hline 4Q 2014 & 232 & 6.68 & - & 450 & 8.04 & & 359 & 7.62 & 2 \\
\hline 1Q 2015 & 224 & 6.62 & 4 & 434 & 8.21 & - & 427 & 8.89 & - \\
\hline 2Q 2015 & 238 & 6.94 & - & 414 & 7.80 & - & 350 & 6.98 & 2 \\
\hline 3Q 2015 & 201 & 5.98 & - & 414 & 7.72 & - & 396 & 7.85 & - \\
\hline 4Q 2015 & 187 & 5.51 & 3 & 386 & 6.94 & 4 & 329 & 6.79 & - \\
\hline Jan.-Feb. 2016 & 120 & 5.61 & & 292 & 8.17 & & 225 & 6.78 & 3 \\
\hline \multicolumn{10}{|c|}{ Number of Readmission Rate Cycles } \\
\hline 2 Quarters & & & 1 & & & 3 & & & 4 \\
\hline 3 Quarters & & & 2 & & & 0 & & & 1 \\
\hline 4 Quarters or M & More & & 1 & & & 1 & & & 0 \\
\hline
\end{tabular}

quarters before rates increased. The data demonstrated that the reductions were sporadic rather than sustained trends over extended periods of time.

Additional study data demonstrated that the impacts of these reductions in readmissions on the inpatient adult medicine and surgery censuses of the hospitals were limited. Between the first quarter of 2013 and the fourth quarter of 2015, the number of readmissions in the combined hospital declined by 170 . This amounted to a reduction of 1190 inpatient days or an average daily census of 3.3 patients.

The limited nature of the reduction of readmissions on the inpatient census of the hospitals probably resulted from a combination of factors. The interest of providers in improving outcomes and the impact of payer reimbursement penalties were probably positive influences. The absence of alternatives to hospital services in the community and the fact that hospitals were still being reimbursed for individual readmissions may have slowed the process.

\section{Discussion}

Historically, efforts to improve the efficiency of health care in the United States have included programs that reduced hospital utilization. Because hospitals are associated with relatively high costs per patient, these initiatives have been a logical focus of efforts to improve efficiency.

This study reviewed a number of these programs in the hospitals of Syracuse, New York over extended time periods. It involved data indicators that were largely under the control of hospitals and their nursing and administrative staffs as well as programs where there was less provider control.

During the period of the study, large reductions in inpatient lengths of stay were generated in the Syracuse hospitals, contributing to a decline in the average daily adult medicine and adult surgery census of 140 patients. Inpatient stays required some involvement with long term care services, but for a minority of patients. Reductions in patient days related to post admission complications were also included in these developments.

The study suggested that efforts to reduce inpatient admissions in the Syracuse hospitals had more limited results. The area's hospital admission rate was conservative, but approximately 2000 discharges per year above that of Rochester, New York. Inpatient readmissions for adult medicine and surgery declined slowly, producing 
a reduction of a few patients in the combined inpatient census of the hospitals.

The limited hospital admission rate resulted from the fact that the Syracuse area had constrained the development of inpatient hospital capacity in previous decades. This development reduced the potential for excess hospital admissions, especially for elderly patients. It was supported by a small managed care organization developed at the initiative of the hospitals. Since the 1990s, however, the local health system did not include a local managed care plan or extensive penetration by managed care plans from other areas.

To a large extent, the lack of a recent impact on hospital admissions or readmissions in the Syracuse hospitals resulted from the absence of provider or payer efforts to develop alternative services in the community where the impact of hospital nursing and administrative managers leave off. The area's primary care system has not taken a strong interest in reducing hospital admissions. Patients with chronic diseases and other conditions that require additional treatment are frequently referred to hospital emergency departments, often resulting in inpatient admission. The area's home health and nursing home providers have not supported the development of services that could avoid hospital admissions. Support for the modest programs that have been developed has come from the hospitals. There has been no payor involvement in these efforts.

This situation is probably most prevalent in small metropolitan areas such as Syracuse. These communities frequently lack the patient volume and provider resources to develop alternative services to hospitalization for individual providers.

From this information it is recommended that, if the experience of the Syracuse hospitals is typical, improvement of the efficiency of community health care systems will require creativity and resources from providers. These organizations, through their administrative and nursing staffs, have the experience with the mechanics of health care that is necessary to develop needed services. Although hospitals and other providers are frequently in competition, cooperation among them in small communities may be necessary to generate the caregiving resources required.

From this information it is recommended that, health care payors assume an active role in these efforts. If genuine improvements in health care efficiency and outcomes are to occur, payors need to invest time and financial resources in this process. They cannot take the position that paying for services in their traditional roles is enough. The development of additional services in small metropolitan areas such as Syracuse, New York will require substantial payor investment in planning and demonstration activities.

Additional research at the community level is needed to generate information that will contribute to improvements in the efficiency of care. Studies at the community level can contribute valuable information concerning a wide range of potential solutions.

\section{Limitations}

The information and conclusions identified in this study were limited to the indicators and data identified. These included lengths of stay in the Syracuse hospitals for adult medicine and adult surgery in 1998 through 2014 and Potentially Preventable Complications rates in two of the Syracuse hospitals for 2009-2015. They also included resident inpatient hospitalization rates per 1000 population in New York State metropolitan areas for 2007-2015 and Potentially Preventable Readmissions for adult medicine and adult surgery patients in the Syracuse hospitals for 2013 through 2016.

The conclusions of this study were based on data for these indicators and time periods. They are limited to the experiences of the hospitals of Syracuse, New York within these parameters.

\section{References}

[1] Dentzler, S. (2011) Urgent Measures for an Old Problem. Health Affairs, 30, 1626. http://dx.doi.org/10.1377/hlthaff.2011.0961

[2] Auerbach, D.L. and Kellermann, A.L. (2011) A Decade of Health Care Cost Growth Has Wiped Out Real Income Gains for an Average US Family. Health Affairs, 30, 1630-1636. http://dx.doi.org/10.1377/hlthaff.2011.0585

[3] Cushing, W.T. (2004) Extra Hospital Days Can Cost You Plenty. Medical Economics, 81, 83.

[4] Friedman, B., De La Mare, J., Andrews, R. and McKenzie, D.H. (2002) Practical Options for Estimating the Costs of Hospital Stays. Journal of Health Care Finance, 291, 1-12.

[5] Fuller, R.L., McCullough E.C., Bao, M.Z. and Averill, R.F. (2009) Estimating the Costs of Potentially Preventable Hospital Acquired Complications. Health Care Financing Review, 30, 17-32. 
[6] Sheng, W.H., Wang, J.T., Lu, D.C., Chie, W.C., Chen, Y.S. and Chang, S.C. (2005) Comparative Impact of Hospital Acquired Infections on Medical Costs, Length of Hospital Stay, and Outcomes between Community Hospitals and Medical Centres. Journal of Hospital Infections, 59, 205-214. http://dx.doi.org/10.1016/j.jhin.2004.06.003

[7] Skinner, J., Chandra, A., Goodman, D. and Fisher, E.S. (2009) The Elusive Connection between Health Care Spending and Quality. Health Affairs, 28, 1256-1258. http://dx.doi.org/10.1377/hlthaff.28.1.w119

[8] Jencks, S.F., Williams, M.V. and Coleman, E.A. (2011) Rehospitalizations among Patients in the Medicare Fee for Service Program. New England Journal of Medicine, 364, 1582. http://dx.doi.org/10.1056/NEJMx110014

[9] Rau, J. (2012) Medicare to Penalize 2211 Hospitals for Excess Readmissions. Kaiser Health News.

[10] Lagoe, R., Pasinski, T., Kronenberg, P., Quinn, T. and Schaengold, P. (2006) Linking Health Services at the Community Level. Canada Health Care Quarterly, 9, 60-65. http://dx.doi.org/10.12927/hcq..18229

[11] Lagoe, R. and Lagoe, R. (2014) Tracking the Sustainability of Improvements in Hospital Outcomes. Advances in Bioscience and Biotechnology, 5, 895-902. http://dx.doi.org/10.4236/abb.2014.511104

[12] Lagoe, R.J. and Westert, G.P. (2010) Evaluation of Inpatient Hospital Complications: A Planning Approach. Health Services Research, 10, 200. http://dx.doi.org/10.1186/1472-6963-10-200

[13] Lagoe, R.J., Westert, G.P., Kendrick, K., Morreale, G. and Mnich, S. (2005) Managing Hospital Length of Stay Reduction: A Multihospital Approach. Health Care Management Review, 30, 89-92. http://dx.doi.org/10.1097/00004010-200504000-00002

[14] Goldfield, N.I., McCullough, E.C, Hughes, J.S., Tang, A.M., Eastman, B., Rawlins, L.K. and Averill, R.F. (2009) Identifying Potentially Preventable Readmissions. Health Care Financing Review, 30, 75-92.

\section{Submit or recommend next manuscript to SCIRP and we will provide best service for you:}

Accepting pre-submission inquiries through Email, Facebook, LinkedIn, Twitter, etc.

A wide selection of journals (inclusive of 9 subjects, more than 200 journals)

Providing 24-hour high-quality service

User-friendly online submission system

Fair and swift peer-review system

Efficient typesetting and proofreading procedure

Display of the result of downloads and visits, as well as the number of cited articles

Maximum dissemination of your research work

Submit your manuscript at: http://papersubmission.scirp.org/ 